\title{
Use of numerical modeling methods in desing of combined rectification column
}

\author{
Ramilya Ibragimova ${ }^{1}$, Vitaliy Afanasenko ${ }^{1, *}$, Gleb Kudryavtsev ${ }^{1}$, and Denis Mazidullin ${ }^{1}$ \\ ${ }^{1}$ Ufa State Petroleum Technological University, 1, Kosmonavtov St. , Ufa, 450062, Russia
}

\begin{abstract}
The article is devoted to the study of methods for modeling the operation of rectification columns using the HYSIS application software package. Such studies are very important not only for design, but also for the functioning of existing industries. The article proposes to use for combining nozzle devices in the concentration part of the column, and plate-shaped structures in the distant part of the column for more efficient and stable operation of distillation columns. To determine the hydrodynamic parameters of the operation of distillation column, a technique of determining the range of stable loads and the position of the operating point inside or outside the range of stable loads was taken. A column model was constructed using the HYSYS software package for separating gas mixtures with various contact devices: sieve trays, Rashig ring nozzles. Experiments for the same type and combined contact devices were carried out and their comparison was carried out in terms of hydraulic calculation and operating range. As a result of experiments with the use of the HYSYS software package, it was shown that the combined arrangement of contact devices can provide a stable hydraulic mode, in contrast to the use of similar contact devices.
\end{abstract}

\section{Introduction}

The development of modern technological processes is impossible without the use of software products for modeling, which have a high accuracy in the description of parameters and allow research of model processes without significant material and time costs. Such studies are very important not only for design, but also for the functioning of existing industries, as they allow you to take into account the influence of most external factors [1].

Since the mid-1990s, instrumental systems of problem-oriented programs Aspen, Hysys, PRO-II, and CHEMCAD have been widely used to solve the indicated problems of computer modeling of complex chemical-technological systems. Such systems allow you to create block computer models of individual chemical-technological processes and complex systems as a whole to solve the problems of analysis and optimization of existing plants quickly and reliably, as well as the tasks of synthesizing energy-saving chemicaltechnological systems of new designed plants.

\footnotetext{
* Corresponding author: afanasenko.v.g@yandex.ru
} 
Hysys software is designed for process modeling to optimize the design of circuit solutions of complex systems. In addition to static modeling of technological schemes, the program allows in the same environment to perform dynamic modeling of individual processes and the entire technological chain, as well as to develop and debug process control schemes. It is possible to carry out calculations of the main structural characteristics of the equipment.

Currently, there are a number of software systems for modeling technological processes for the collection, preparation and processing of hydrocarbons: Aspen HYSYS, PetroSIM, Gazkondneft [2-4], etc. For newly designed units, it includes:

- physico-chemical properties of oil, produced water, oil gas, natural (break-through) gas, their compositions;

- profiles of oil, liquid, gas and water injection;

- requirements for the quality of oil treatment at the points of delivery, gas, water for injection into the reservoir;

- parameters at the inlet of the units (pressure and temperature) and their dynamics.

In the case of modeling an existing facility, an analysis of its technological scheme and technological mode for the historical period allows us to determine the basic laws of the facility's operation, adapt the model taking into account the hydrogasdynamic characteristics of equipment and pipelines, and more accurately predict the future behavior of the system in terms of possible changes [5-9].

The nozzle and plate contact devices are completely different in principle of operation, and their suitability for specific separation processes is different. The main difference is that in the packed column continuous contact is made between the gas and the liquid, while stepwise contact occurs in the tray [10-19].

We proposed using combination nozzles in the concentration part of the column for more efficient and stable operation of distillation columns, and plate-shaped structures in the distant part of the column.

The feasibility of this solution is quite logical: in the distant part, a large fluid load and disk-shaped structures have a wider range of operation.

A feature of nozzles is the ability to work with large loads of gas and small loads of liquid, and this is just typical for the concentration part of the column.

We set the task to use modern numerical methods, in particular the HYSYS program, to simulate a combined column.

At the first stage, a range of stable loads was determined for simple columns loaded with the same type of design of contact devices for the separation of gas-condensate mixture.

The composition of the hydrocarbon mixture is shown in Figure 1.

\begin{tabular}{|c|c|c|c|c|c|}
\hline Worksheet & \multicolumn{5}{|c|}{\begin{tabular}{l|l|} 
Attachments & Dynamics
\end{tabular}} \\
\hline \multicolumn{2}{|c|}{ Worksheet } & & Mole Fractions & Vapour Phase & Liquid Phase \\
\hline \multirow{2}{*}{\multicolumn{2}{|c|}{$\begin{array}{l}\text { Conditions } \\
\text { Properties }\end{array}$}} & Methane & 0,1955 & 0.5714 & 0.0544 \\
\hline \multirow{2}{*}{\multicolumn{2}{|c|}{ Composition }} & Ethane & 0,1462 & 0.2470 & 0.1084 \\
\hline & & Propane & 0,1058 & 0.0837 & 0.1141 \\
\hline \multirow{2}{*}{\multicolumn{2}{|c|}{$\begin{array}{l}\text { Oil \& Gas Feed } \\
\text { Petroleum Assay }\end{array}$}} & i-Butane & 0,1076 & 0.0428 & 0.1319 \\
\hline & & n-Butane & 0,0983 & 0.0296 & 0.1241 \\
\hline \multicolumn{2}{|c|}{$\begin{array}{l}\text { K Value } \\
\text { User Variables }\end{array}$} & i-Pentane & 0,0891 & 0.0125 & 0.1179 \\
\hline \multirow{4}{*}{\multicolumn{2}{|c|}{$\begin{array}{l}\text { Notes } \\
\text { Cost Parameters } \\
\text { Normalized Yields }\end{array}$}} & n-Pentane & 0,0768 & 0.0084 & 0.1025 \\
\hline & & n-Hexane & 0,0903 & 0.0036 & 0.1228 \\
\hline & & n-Heptane & 0,0517 & 0.0008 & 0.0708 \\
\hline & & n-Octane & 0,0387 & 0.0002 & 0.0531 \\
\hline
\end{tabular}

Fig. 1. The composition of the hydrocarbon mixture is shown: temperature $32 \mathrm{C}$, pressure $1.7 \mathrm{MPa}$, mole discharge of 2428 kilograms / hour.

The column layout with the basic input data is presented in Figure 2: 


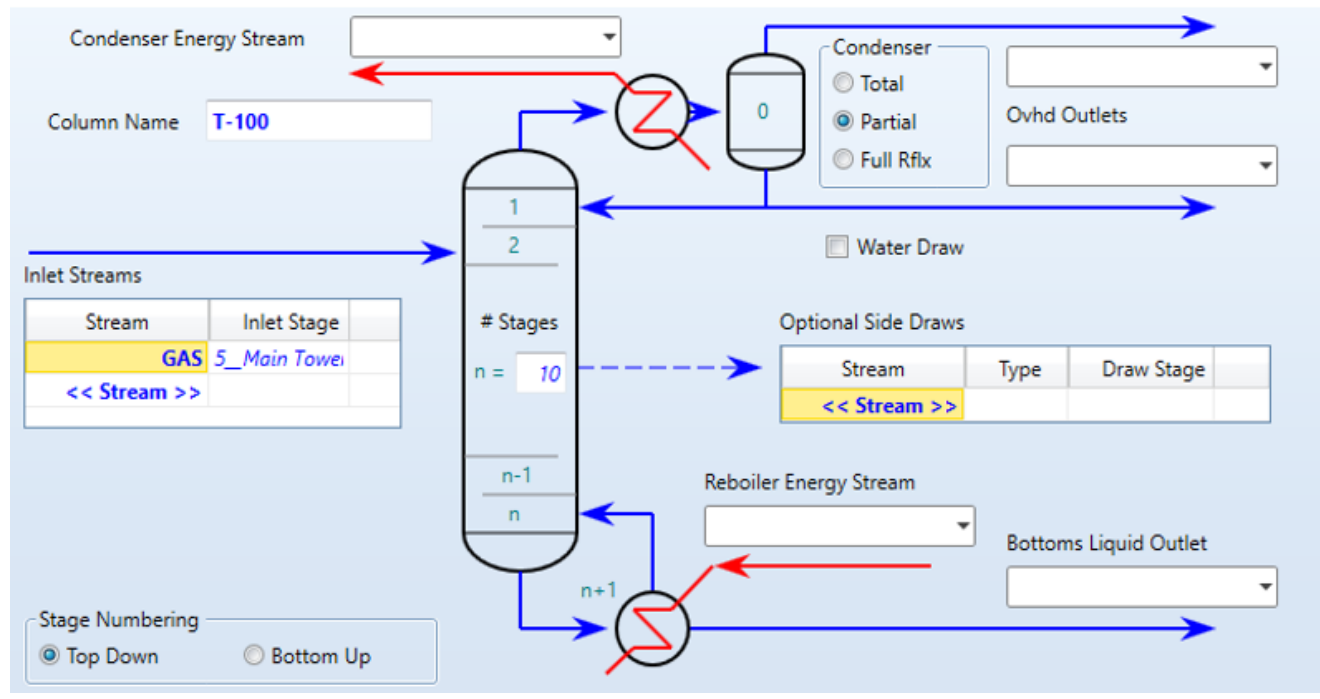

Fig. 2. Scheme of the column for the separation of the gas-condensate mixture.

As contact devices, sieve plates for mass transfer processes in this column were selected.

To determine the hydrodynamic parameters of the distillation column, a technique of determining the range of stable loads and the position of the working point inside or outside the range of stable loads was taken.

As can be seen in Figure 3, the column mode with this choice of contact devices is violated, in this case, the operation of the concentration part of the column is unstable during the operation of the sieve plates.

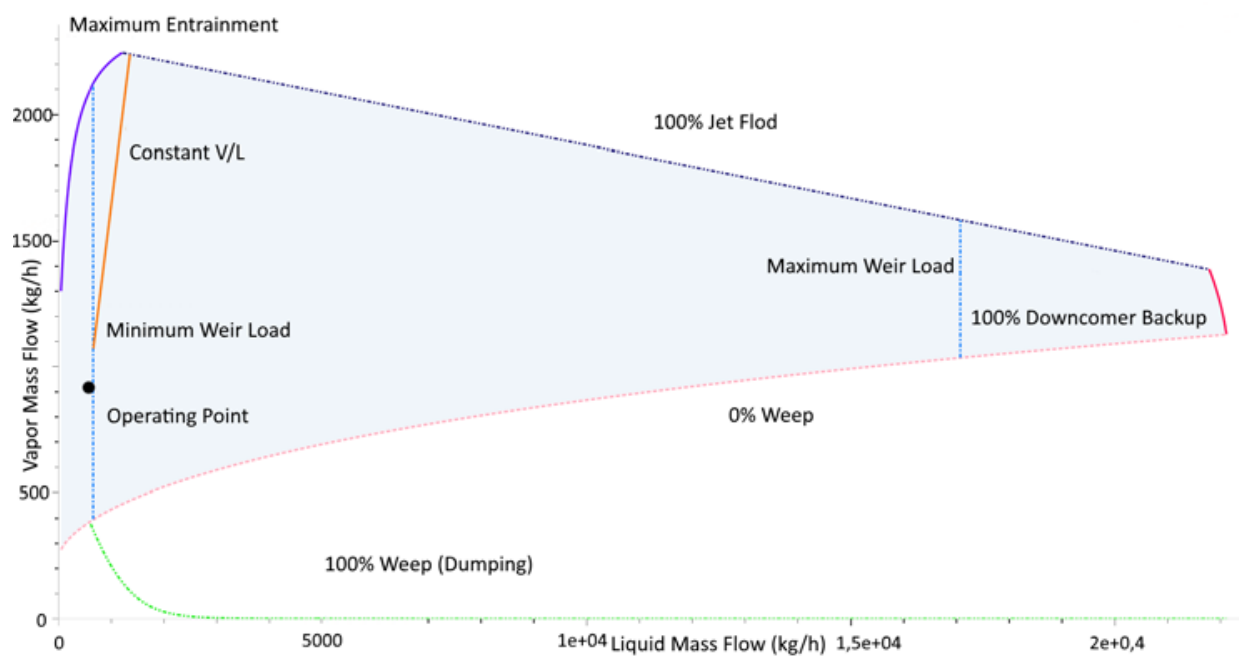

Fig. 3. Diagram of the hydraulic parameters of the plate column with sieve contact devices.

Figure 3 shows the area of stable operation of the plate, limited by the shaded field. The operating point that determines the operating parameters of the plate is outside the zone of stable operation. 
Similarly, experiments were conducted under otherwise equal conditions, but with the use of nozzle contact devices - Rashig rings. The parameters of the nozzle of the Rashig rings are taken from the built-in library of the software package.

The experimental results show that when using only Rashig rings as contact devices, the operating mode of the stripping part of the column under these conditions is unstable, which is confirmed by the graph of the range of the packed column (Figure 4).

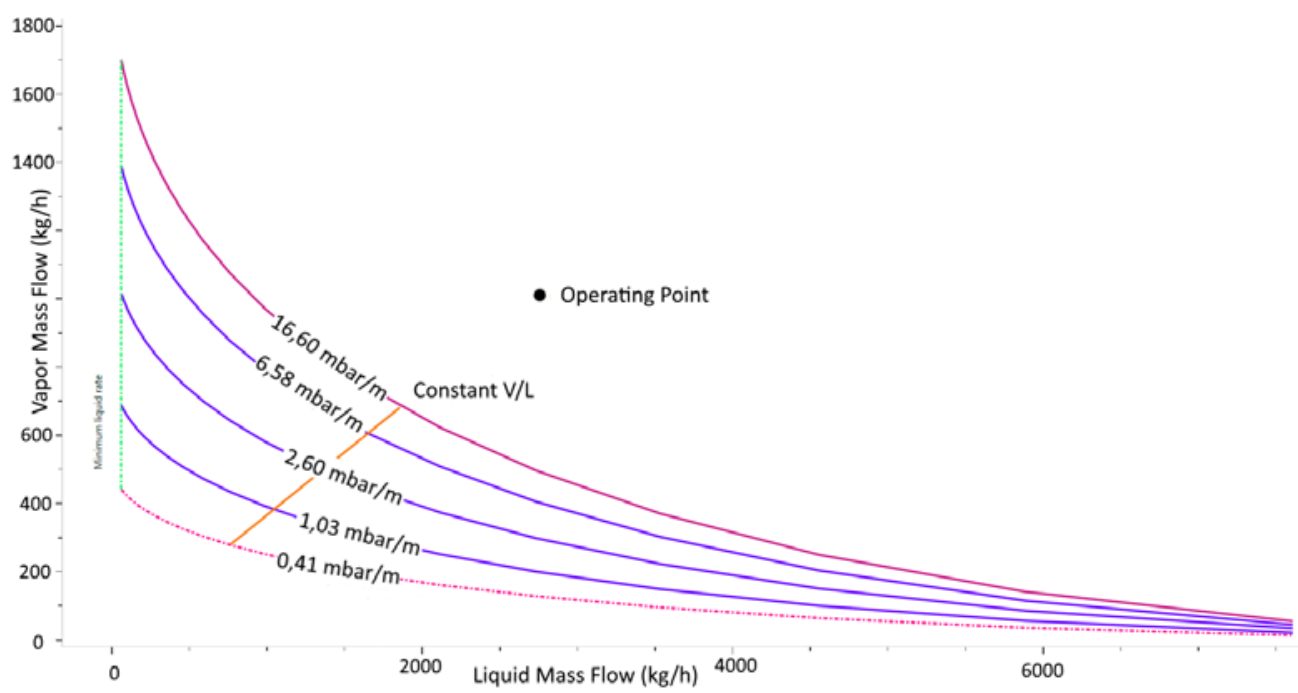

Fig. 4. Diagram of the hydraulic parameters of the column.

Analysis of the diagram showed that the working point of the column of the stripping part of the column is beyond the range of operation. This is due to the fact that the pressure drop over the nozzle exceeded the permissible values.

We use the constructed column, but we will install the nozzle contact devices of the Rashig rings at the top of the column, and we will establish the seive contact devices at the bottom of the column and analyze the data obtained.

An analysis of Figures 4 and 5 shows that the combined column with nozzles in the concentration part and plates in the stripping part of the column provides a specified range of operation over the entire height of the column. The hydraulic mode of operation of the combined column is stable.

\section{Conclusion}

A simple column model was constructed using the HYSYS software package for separating gas mixtures with various contact devices: sieve plates, Rashig ring nozzles.

Experiments for the same type and combined contact devices were carried out and their comparison was carried out in terms of hydraulic calculation and operating range.

As a result of experiments using the HYSYS software package, it was proved that the combined arrangement of contact devices can provide a stable hydraulic mode, in contrast to the use of similar contact devices. 

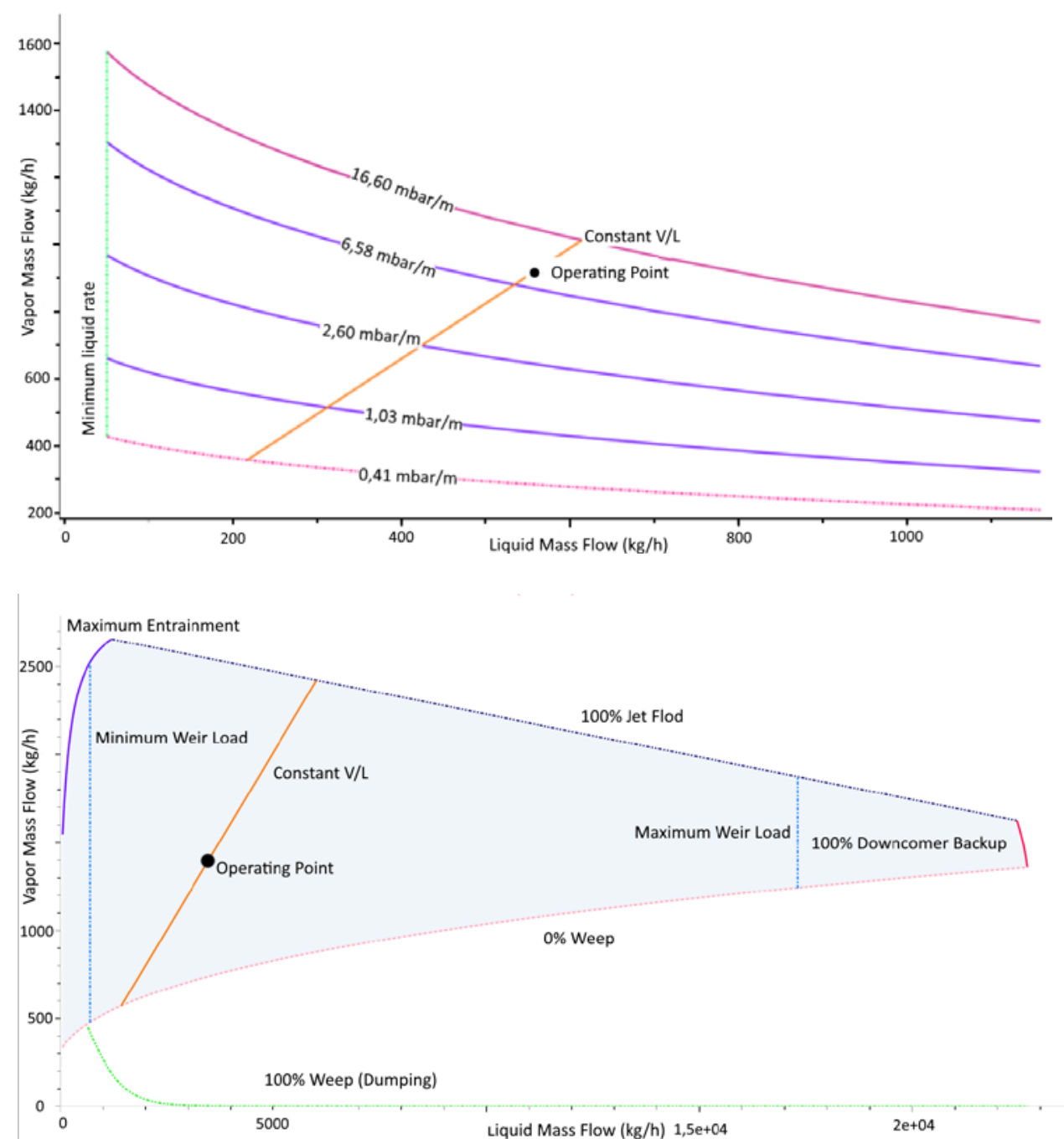

Fig. 5. - Diagram of hydraulic parameters for a combined column for: a) Rashig rings; b) a seive plate

\section{References}

1. V.N. Mamin The study of the hydrodynamics of combined plates of distillation columns // Scientific works of KubGTU, 4 (2015)

2. N.N. Ziyatdinov, A.A. Karavanov, R.S. Leontyeva, A.V. Mingalieva Optimization of the operation mode of the rectification unit of the hydrotreatment unit for heavy coking gas oil in the environment of the HYSYS modeling program // Bulletin of the Technological University, v. 19(22), pp. 112-115 (2016)

3. M. Short, A. J. Isafiade, L. T. Biegler, Z. Kravanja Synthesis of mass exchanger networks in a two-step hybrid optimization strategy// Chemical Engineering Science, v.178, pp. 118-135 (2018) 
4. N. R. Uliana, L. A. Kuhl, M. B. Quadri, J. V. Oliveira Model and simulation of a packed resin column for biodiesel purification// Renewable Energy, v. 126, pp. 10741084 (2018)

5. R.R. Ibragimova, O.S. Murygin Use of criteria factors in modeling the hydrodynamics of mass transfer processes. The world community: problems and solutions: Sb.nauchn.st.- Ufa: Publishing house UGNTU, 27 (2010).

6. A.V. Arguchintsev, V.P. Poplevko Optimization of the rectification process in the column // Bulletin of St. Petersburg University. Applied Mathematics. Computer science. Management processes, 3, pp. 3-9 (2012)

7. R.B. Tukaeva, V.G. Afanasenko, P.A. Kulakov Development of a technique of the automated construction of 3D models of standard mass transfer trays// MATEC Web of Conferences, v. 224(04027) (2018)

8. J. Ramírez, S. Moghimi, J. M. Restrepo, S. Venkataramani Modelling the mass exchange dynamics of oceanic surface and subsurface oil// Ocean Modelling, v.129, pp. 1-12 (2018)

9. A.V. Dmitriev, O.S. Makusheva, K.V. Dmitrieva, A.N. Nikolaev, Contact mass exchanger to increase output of active tower units// Chemical and Petroleum Engineering, 47(5-6), pp. 319-323 (2011)

10. M.A. Zakirov, Sh.B. Gataullin Modernization of a packed column for rectification of a mixture of glycols // Bulletin of the Technological University, v. 19( 23), pp. 40-42 (2016)

11. C. B. Vik, J. Solsvik, M. Hillestad, H. A. Jakobsen A multifluid-PBE model for simulation of mass transfer limited processes operated in bubble columns// Computers \& Chemical Engineering, v. 110, pp. 115-139 (2018)

12. J. Solsvik Lagrangian modeling of mass transfer from a single bubble rising in stagnant liquid// Chemical Engineering Science, v. 190, pp. 370-383 (2018)

13. O.S. Dmitrieva, I.N. Madyshev, A.V. Dmitriev, Determination of the Heat and Mass Transfer Efficiency at the Contact Stage of a Jet-Film Facility// Journal of Engineering Physics and Thermophysics, pp. 1-6 (2017)

14. M. A. Staedter, S. Garimella Heat and mass transfer in microscale diabatic distillation columns for ammonia-water desorption and rectification// International Journal of Refrigeration, v. 95, pp. 10-20 (2018)

15. N.A. Voinov, D.A. Zemtsov, O.P. Zhukova Investigation of thermal distillation in a column with low mass transfer at the steps // Theoretical Foundations of Chemical Technology, v. 51(2), pp. 174-181 (2017)

16. V.S. Kuleshov, K.V. Moiseev, S.F. Khizbullina, K.I. Mikhaylenko, S.F. Urmancheev Convective Flows of Anomalous Thermoviscous Fluid// Mathematical Models and Computer Simulations, 10(4), pp. 529-537 (2018)

17. P.A. Kulakov, A.A. Kutlubulatov, V.G. Afanasenko Forecasting of the hydraulic fracturing efficiency as components of its design optimization// SOCAR Proceedings, 2, pp. 41-48 (2018)

18. A.V. Dmitriev, O.S. Dmitrieva, I.N. Madyshev, Optimal Designing of Mass Transfer Apparatuses with Jet-Film Contact Devices// Chemical and Petroleum Engineering, 53(7-8), pp. 430-434 (2017)

19. D.A. Zemtsov, N.A. Voinov, O.P. Zhukova, N.Yu. Kozhukhova, Yu.D. Alash-kevich Intensification of the rectification process in a low resistance column // Chemical Industry, v. 94(5), pp. 255-258 (2017) 